\title{
Pembibitan Kopi Liberika di Desa Puralaksana, Kecamatan Way Tenong, Lampung Barat
}

\author{
Rusdi Evizal $^{1}$, Agus M. Hariri ${ }^{1}$, Sugiatno' ${ }^{1}$, Fembriarti Erry Prasmatiwi ${ }^{2}$ \\ ${ }^{1}$ Agroteknologi, Universitas Lampung, Bandar Lampung, 35145, Lampung, Indonesia \\ ${ }_{2}$ Agribisnis, Universitas Lampung, Bandar Lampung, 35145, Lampung, Indonesia
}

\begin{abstract}
.
Lampung Barat merupakan sentra produksi kopi Robusta, antara lain di Kecamatan Sumberjaya. Untuk meningkatkan adaptasi kopi Robusta terhadap variabilitas curah hujan dan keadaan lahan marginal, petani di Desa Puralaksana Kecamatan Sumberjaya bertanam kopi Liberika, baik untuk menghasilkan kopi Liberika maupun untuk disambung sebagai batang bawah pada sistem interspesifik Robusta/Liberika. Tujuan kegiatan Pengabdian kepada Masyarakat ini adalah: (1) Meningkatkan pengetahuan dan keterampilan anggota kelompok tani Makmur Utama, Pekon Puralaksana, Way Tenong, Lampung Barat dalam budidaya kopi sambung Robusta/Liberika dan pemilihan pohon induk kopi Liberika, (2) Meningkatkan pengetahuan dan keterampilan anggota kelompok tani Makmur Utama, Pekon Puralaksana, Way Tenong, Lampung Barat dalam pembibitan kopi Liberika. Kesimpulan kegiatan PKM ini adalah: (1) Pengabdian masyarakat "Demplot Pembibitan Kopi Liberika di Desa Puralaksana, Kecamatan Way Tenong, Sumberjaya, Kabupaten Lampung Barat sudah dilaksanakan dengan peserta dari Kelompok Tani Makmur Utama melalui kegiatan penyuluhan, FGD, anjangsana dan anjangkarya dan pendampingan penguatan kelompok, (2) Pengabdian ini dapat meningkatkan pengetahuan dan keterampilan petani dalam pembibitan kopi Liberika dan budidaya kopi sambungan Robusta/Liberika untuk meningkatkan ketahanan dan produktivitas kopi pada cuaca ekstrim dengan skor 65 berkategori baik.
\end{abstract}

Keywords.

Kopi Liberika, pembibitan, pohon induk, grafting, Robinson

\section{PENDAHULUAN}

\section{Analisis Situasi}

Provinsi Lampung merupakan salah satu sentra kopi robusta Indonesia yang memiliki luas areal 158 ribu ha yaitu $20 \%$ dari areal robusta nasional, yang menghasilkan sekitar 107 ribu ton biji kopi per tahun. Ekspor kopi Indonesia pada tahun 2017 mencapai jumlah 467 ribu ton dengan nilai 1.186 ribu USD [1]. Kabupaten Lampung Barat memiliki areal yang terluas yaitu 53.878 ha antara lain terdapat di Kecamatan Way Tenong dengan luas areal mencapai 4.769 ha [2]. Kopi Lampung di pasar internasional dikenal sebagai Lampung

\section{* Corresponding author: rusdi.evizal@fp.unila.ac.id}

Received 5 November 2021; Received in revised form 16 November 2021; Accepted 17 November 2021 Available online 28 December 2021

Lembaga Penelitian dan Pengabdian Kepada Masyarakat

Universitas Lampung 
Coffee dan diakui sebagai kopi Robusta yang berkualitas tinggi dengan citarasa yang khas.

Kecamatan Way Tenong terdiri dari 9 antara lain pekon Puralaksana dengan luas 699 ha dan jumlah penduduk 4.112 jiwa. Tata guna lahan di Kecamatan Way Tenong didominasi oleh perkebunan kopi dan hutan lindung dengan perincian sebagai berikut: perkebunan 11.474 ha, hutan lindung 9.791 ha, persawahan 425 ha, ladang/tegal 683 ha, pekarangan/pemukiman 1.125 ha, empang 95 ha, lain-lain 162 ha. Selain ditanam secara monokultur, kopi ditanam secara campuran seperti dengan lada, cengkeh, dan kakao [3].

Kopi termasuk tanaman yang rentan terhadap gejala perubahan iklim yang ditandai antara lain dengan kenaikan temperatur udara dan meningkatnya variabilitas dan ketidakmenentuan baik berupa bulan kering yang panjang, intensitas hujan yang tinggi, serta meningkatkan keterjadian dan kedahsyatan cuaca ekstrim yang menurunkan produksi kopi [4]. Pembungaan dan pembuahan kopi menghendaki kondisi cuaca yang mendukung yaitu adanya musim kemarau 1-3 bulan yang di dalam masih terdapat hujan kiriman. Petani di Lampung lebih merasakan dampak cuaca ekstrim yang terjadai pada 4 tahun terakhir dan berupaya untuk beradaptasi antara lain dengan cara bertanam kopi di lahan dan kultivar yang lebih cocok, umumnya di wilayah pegunungan yang lebih tinggi, sementara lahan kopi yang menjadi yang menjadi kurang cocok ditanami secara campuran dan bahkan diganti dengan komoditas lain yang lebih menguntungkan [5,6].

Agar tanaman kopi lebih tahan terhadap cekaman lingkungan terutama kemarau, lahan yang kurang subur, dan tahan penyakit puru akar, maka sebagian petani Pekon Puralaksana bertanam kopi Liberika var Robinson yang digunakan sebagai batang bawah untuk disambung dengan kopi Robusta. Sebagian petani memelihara kopi Liberika Robinson untuk dipanen buahnya dan dibuat kopi bubuk Liberika yang bercitarasa khas yaitu beraroma Nangka sebagai diversifikasi produk selain kopi Robusta. Ragam varietas Robinson cukup banyak sehingga untuk mengembangkan kopi Liberika Robinson, petani belum memiliki keterampilan memilih pohon induk dan kultivar untuk digunakan sebagai bahan pembibitan.

\section{Identifikasi dan Perumusan Masalah}

a. Anggota kelompok tani Makmur Utama kurang memahami budidaya kopi sambung Robusta/Liberika sebagai upaya adaptasi perubahan iklim.

b. Anggota kelompok tani Makmur Utama kurang memahami pemilihan pohon induk dan kultivar kopi Liberika.

c. Anggota kelompok tani Makmur Utama kurang memahami pembibitan yang menghasilkan bibit kopi Liberika yang bermutu.

\section{Tujuan Kegiatan}

a. Meningkatkan pengetahuan dan keterampilan anggota kelompok tani Makmur Utama, Pekon Puralaksana, Way Tenong, Lampung Barat dalam budidaya kopi sambung Robusta/Liberika dan pemilihan pohon induk kopi Liberika.

b. Meningkatkan pengetahuan dan keterampilan anggota kelompok tani Makmur Utama, Pekon Puralaksana, Way Tenong, Lampung Barat dalam pembibitan kopi Liberika.

\section{Manfaat Kegiatan}

a. Anggota kelompok mendapatkan pengetahuan dan keterampilan dalam memahami penerapan adaptasi berkebun kopi pada cuaca ekstrim.

b. Kelompok melakukan transfer pengetahuan kepada anggota dalam upaya 
meningkatkan ketahanan dan produktivitas kopi pada cuaca ekstrim.

\section{BAHAN DAN METODE}

\section{Kerangka Pemecahan Masalah}

Dari analisis situasi dan prasurvei yang telah dilakukan sebelumnya, diketahuai bahwa berkebun kopi merupakan mata pencarian utama bagi penduduk Pekon Puralaksana, Way Tenong, Lampung Barat. Kendala budidaya kopi Robusta saat ini antara lain adalah semakin kuurangnya kesuburan tanah dan adanya musim atau cuaca ekstrim. Produksi kopi tahun 2020 dipengaruhi oleh kemarau panjang tahun 2019 yang mencapai 6 bulan kering. Kebun kopi yang menggunakan kopi Liberika sebagai batang bawah memberikan hasil yang tetap tinggi meskipun terjadi penurunan. Kopi Liberika sebagai batang bawah membuat tanaman kopi lebih tahan kering dan lebih beradaptasi pada lahan yang kurang subur.

Usahatani kopi dirasakan petani menghadapi banyak kendala antara lain fluktuasi harga daan produksi kopi akibat keadaan cuaca ekstrim seperti musim hujan dan musim kemarau yang panjang. Untuk itu petani tidak hanya menggantungkan pendapatan pada usahatani kopi melainkan sistem kebun campuran ini memerlukan pengelolaan dalam penataan tanam dan waktu tanam. Produksi kopi yang lebat bersifat berseling dua tahunan (biennual bearing). Indeks Hasil Bianual ditentukan oleh banyak faktor antara lain faktor genetik, lingkungan (iklim, cuaca, kesuburan), dan praktek pemeliharaan seperti pemangkasan dan pemupukan. Untuk meningkatkan ketahanan produksi kopi dalam cuaca ekstrim maka petani perlu melakukan penyambungan kopi Liberika dengan klon Robusta unggul dan melakukan pemupukan yang tepat.

\section{Metode Pelaksanaan}

Kegiatan ini dilaksanakan dengan metode:

a. Ceramah dan tatap muka

b. Focus Group Discussion (FGD)

c. Pendampingan penguatan kelompok

d. Anjangsana dan anjangkarya

\section{Keterlibatan Mitra}

Keterlibatan mitra kelompok tani Makmur Utama (1) menyediakan lokasi penyuluhan dan FGD, (2) melaksanakan penyuluhan dan FGD, (3) (4) menyebarluaskan hasil-hasil penyuluhan dan FGD kepada petani maju dan kelompok tani di sekitar lokasi pengabdian.

\section{Rancangan Evaluasi}

Pada kegiatan ini akan dilakukan evaluasi yaitu:

a. Evaluasi awal, bertujuan mengetahui sejauh mana pengetahuan dan keterampilan petani dalam meningkatkan ketahanan dan produksi kopi dalam cuaca ekstrim.

b. Evaluasi proses, untuk mengetahui dukungan peserta, kehaditran dan aktifitas peserta kelancaran kegiatan ini mulai dari penyuluhan, FGD, dan penyusunan agroteknologi budidaya kopi campuran.

c. Evaluasi akhir, untuk mengetahui dampak kegiatan, keberlanjutan program, serta manfaat kegiatan terhadap peserta. 


\section{HASIL DAN PEMBAHASAN}

\section{Pembuatan Demplot Pembibitan Kopi Liberika}

Pembuatan demplot pembibitan kopi Liberika dimulai dengan penyiapan benih unggul yang dipanen dari pohon induk kopi Liberika. Buah masak dipanen ketika musim utama panen, bukan dari panen pertama. Buah diseleksi dengan cara dimsukkan dalam air, dan diambil hanya buah yang terendam yang menandakan buah berbiji bernas. Selanjutnya buah dibelah dua dan dianginkan 2 hari, benih siap disemai (gambar 1).
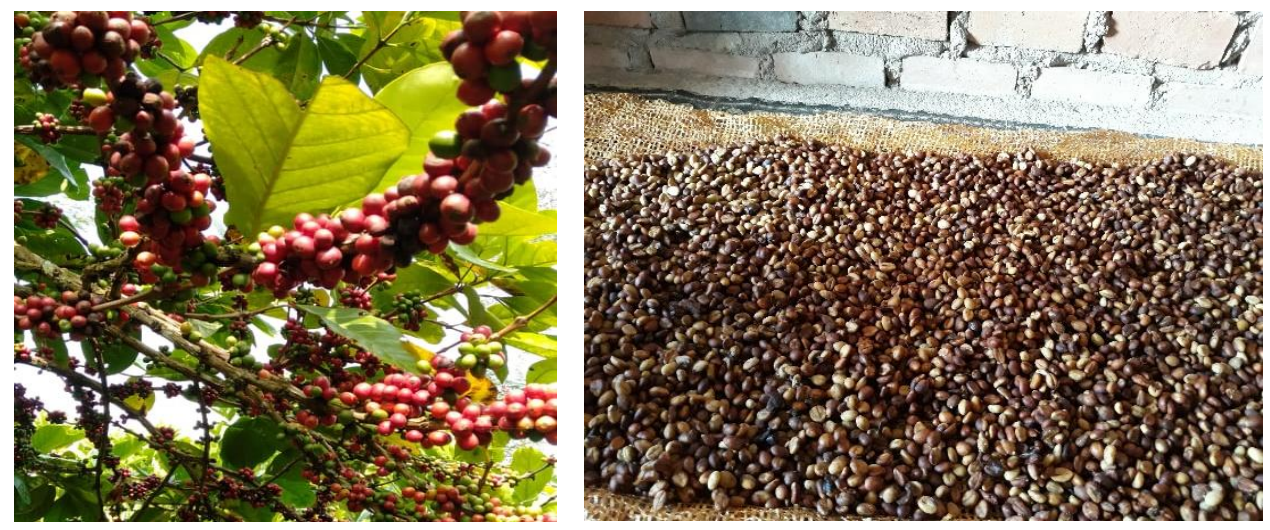

Gambar 1. Penyiapan benih kopi Liberika

Benih disemai di media pasir, disusun jarak $2 \times 2 \mathrm{~cm}$ dan ditutup pasir setebal $1 \mathrm{~cm}$. Benih diberi atap paranet dan disiram setiap hari. Umut 1 bulan benih sudah berkecambah dan pada umur 2 bulan semai dipindah ke dalam polybag berisi campuran tanah, arang sekam, dan kompos (3:1:1 v/v). Bibit disusun di bawah atap paranet dan disiram setiap hari jika hari tidak hujan. Setiap umur 2 bulan dilkukan pemberikan pupuk NPK (15:15:15) sebanyak 1 sendok teh per polybag dengan cara ditabur di dalam polybag. Pada umur 7 bulan bibit berukuran tinggi $30 \mathrm{~cm}$ berdaun 6-8 helai, sudah cukup kuat untuk ditanam di kebun (Gambar 2). Hasil bibit dibagikan kepada anggota yang ingin menanam kopi Liberika di kebun masing-masing, umumnya pada lahan yang sudah kurang subur untuk menyulam kopi Robusta yang mati.
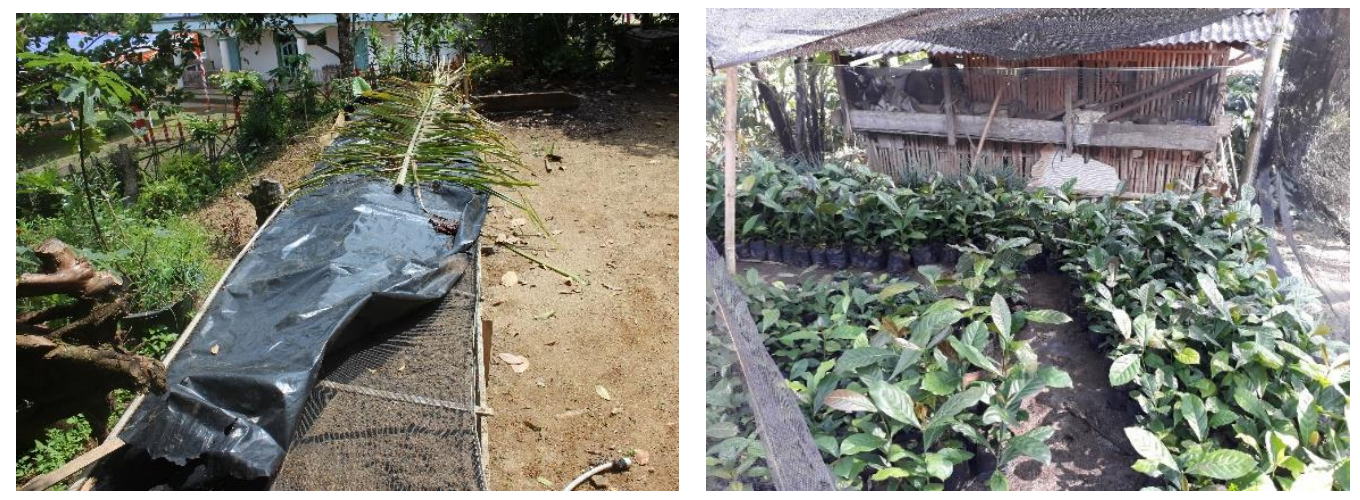

Gambar 2. Demplot pembibitan kopi Liberika di rumah paranet

Selain dibuat demplot di pembibitan atap, dibuat juga demplot pembibitan kopi Liberika di kebun kopi, yaitu memanfaatkan lahan di kebun kopi. Lahan di antara barisan tanaman kopi diolah dan dibuat bedengan, lebar $1 \mathrm{~m}$ dan panjang $15 \mathrm{~m}$. Sebagai naungan adalah tanaman kopi dan pohon naungan kopi. Bibit kopi Liberika hasil semaian ditanam di bedengan tanah 
dengan jarak tanam $30 \times 30 \mathrm{~cm}$ sehingga diperoleh 3 barisan bibit. Sebagai mulsa, bedengan diberi kulit kopi dengan tebal $5 \mathrm{~cm}$. Jika keadaan kering, maka bibit perlu disiram. Ketika memupuk tanaman kopi, maka bibit kopi juga dipupuk dengan cara dikocor dengan konsentrasi larutan $0,2 \%$. Bibit berhasil tumbuh dengan baik, namun sedikit lebih lambat daripada pertumbuhan bibit di bawah atap rumah bibitan karena menerima pemeliharaan yang lebih intensif (Gambar 3).
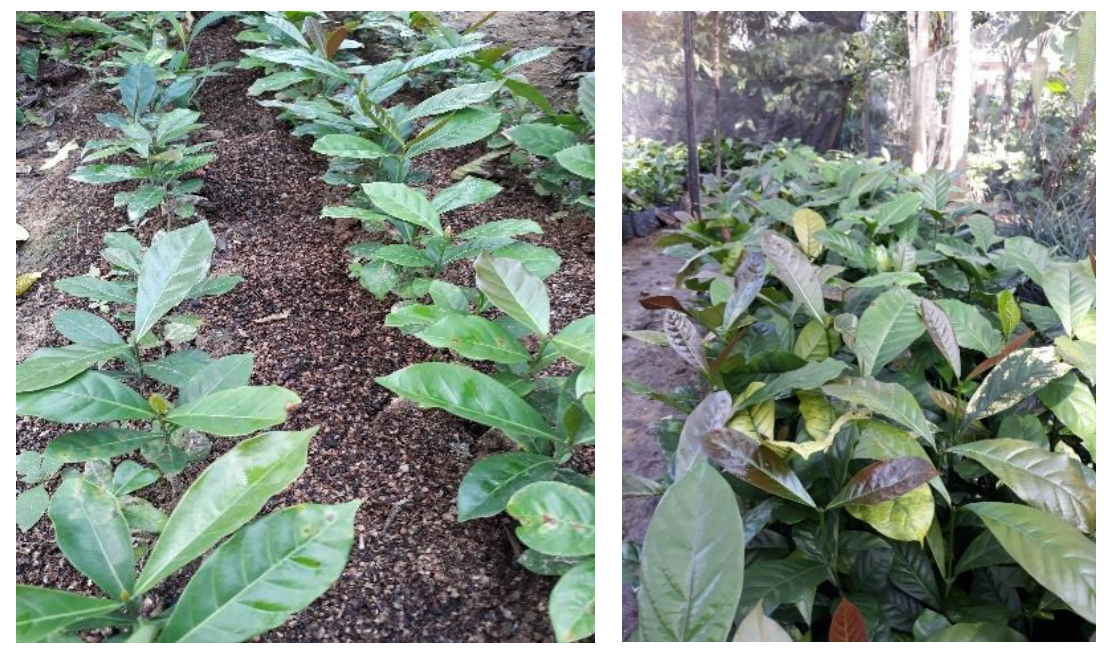

Gambar 3. Demplot pembibitan kopi Liberika di bedengan

\section{Ceramah dan Diskusi Budidaya Kopi Liberika di Lampung}

Penyuluhan diikuti oleh pengurus dan anggota kelompok tani Makmur Utama, pengurus kelompok tani lainnya di sekitar lokasi dan petani maju di Pekon Puralaksana, Kecamatan Way Tenong, Kabupaten Lampung Barat. Sesuai dengan protokol penanggulangan covid19 maka penyuluhan dimulai dengan pembagian masker untuk para peserta, mencuci tangan pakai sabun, duduk berjarak renggang dan dilanjutkan dengan penyampaian materi tentang pembibitan kopi Liberika, pemilihan pohon induk, dan penanaman kopi Liberika. Selain itu dilakukan diskusi dan pembagian bibit kopi Liberika yang siap untuk ditanam dan dilanjutkan dengan anjang sana dan anjang karya.

Dari diskusi teruangkap bahwa anggota kelompok semuanya berkebun kopi Robusta dan menanam kopi Liberika sebagai tanaman sulaman untuk kemudian dilakukan penyambungan dengan kopi Robusta. Kendala budidaya kopi Robusta saat ini antara lain adalah semakin kurangnya kesuburan tanah dan adanya musim atau cuaca ekstrim. Produksi kopi tahun 2020 dipengaruhi oleh kemarau panjang tahun 2019 yang mencapai 6 bulan kering. Kebun kopi yang menggunakan kopi Liberika sebagai batang bawah memberikan hasil yang tetap tinggi meskipun terjadi penurunan. Kopi Liberika sebagai batang bawah membuat tanaman kopi lebih tahan kering dan lebih beradaptasi pada lahan yang kurang subur.

Petani anggota kelompok umumnya memerlukan bibit kopi Liberika untuk menyulam kebun kopi Robusta yang jika disulam dengan bibit kopi Robuta sudah sulit untuk tumbuh. Untuk itu diperlukan pembibitan kopi Liberika secara mandiri oleh petani atau kelompok tani. Dalam pertemuan didiskusikan sumber pohon induk Liberika yang terdapat di lokasi kecamatan dan sekitarnya. Yaitu dipilih pohon induk yang tumbuh subur, berbuah lebat, tidak terserang hama dan penyakit. Meskipun tujuannya sebagai batang bawah, tetapi sebagian petani juga membiarkan tanaman kopi Liberika Robinson berbuah dan dipanen untuk konsumsi sendiri atau dijual dalam bentuk kopi biji. 


\section{FGD Pemilihan Pohon Induk Kopi Liberika}

Pohon induk kopi Liberika yang unggul ditandai dengan buah yang selalau lebat setiap tanah, berumur lebih dari 7-8 tahun, keadaan tajuk pohon bagus, tidak terserang hama dan penyakit, dan di musim kemarau tetap mampu tumbuh dengan baik, bahkan berbuah lebat. Dalam satu kebun, dapat dipilih 5-10\% pohon induk yang unggul.

Varietas kopi Liberika lokal yang ditemukan di sekitar Kecamatan sumberjaya dan Kecamatan Way Tenong antara lain sebagai berikut. Robinson Merah: Buah ukuran sedang, bentuk bulat, diskus sedang, biji kecil, buah masak merah, daun besar memanjang, flush hijau kekuningan, dompolan sedang, dan rapat. Robinson Merah Besar: Buah ukuran besar, bentuk bulat memanjang $(1,36 \times 1,62 \times 1,98 \mathrm{~cm})$, diskus sedang-besar, biji kecil, buah masak merah, daun besar memanjang $(24,4 \times 10,4 \mathrm{~cm})$ flush hijau kekuningan, dompolan sedang, dan rapat, berbunga ulang pada bekas bunga di batang dan cabang (Gambar 4).

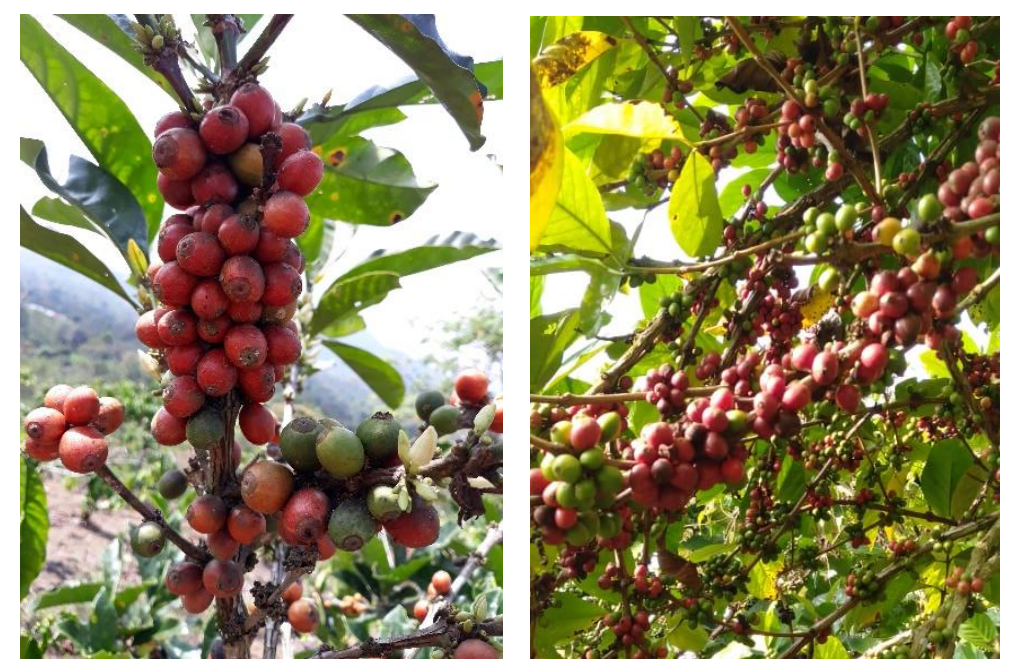

Gambar 4. Pohon induk kopi Liberika

Selain itu ditemukan pula varietas Robinson Daun Panjang: Buah ukuran sedang, bentuk bulat $(1,33 \times 1,59 \times 1,56 \mathrm{~cm})$, diskus besar, biji kecil memanjang, buah masak merah, daun besar memanjang $(25,9 \times 12,3 \mathrm{~cm})$ flush hijau coklat, dompolan sedang, dan rapat. Robinson Daun Lebar: Ukuran buah besar, bentuk agak lonjong $(1,31 \times 1,36 \times 1,56)$, diskus besar, ukuran biji sedang, warna buah masak kuning agak merah, kulit buah lunak, buah tidak terlalu kuat menempel pada tangkai sehingga mudah dipanen, berdaun sangat besar $(14,8 \times 26,1 \mathrm{~cm})$, dompol buah besar dan rapat.

Robinson Merah Kuning: Buah berukuran sedang, buah muda hijau, buah tua kuning dan buah masak merah, dompolan besar, rapat, diskus besar dan jelas, daun besar memanjang, flush hijau kekuningan. Robinson Kuning: Buah berukuran sedang, berwarna hijau ketika muda dan berwarna kuning ketika masak, bentuk bulat, diskus kecil. Daun besar memanjang, flush berwarna hijau kuning. Ukuran dompol sedang dan agak rapat.

\section{Evaluasi Pelaksanaan Program}

Hasil evaluasi kegiatan disajikan pada Tabel 1. Kegiatan mendapat sambutan masyarakat dan demplot berlangsung dengan baik. Pengetahuan/keterampilan petani peserta meningkat dari nilai evaluasi awal rata-rata 2,38 dari skala skor 1-5 dengan skor total 43 yang menunjukkan nilai cukup, meningkat menjadi rata-rata 3,61 dengan skor total 65 yang menunjukkan nilai baik. 
Tabel 1. Evaluasi kegiatan

\begin{tabular}{|c|c|c|c|c|c|c|c|c|}
\hline \multirow[t]{2}{*}{ No } & \multirow{2}{*}{$\frac{\text { Indikator }}{\text { Pengetahuan/keterampilan }}$} & \multicolumn{5}{|c|}{ Skala } & \multirow[t]{2}{*}{$\begin{array}{l}\text { Nilai } \\
\text { awal }\end{array}$} & \multirow[t]{2}{*}{$\begin{array}{l}\text { Nilai } \\
\text { akhi }\end{array}$} \\
\hline & & 5 & 4 & 3 & 2 & 1 & & \\
\hline 1. & Keunggulan tanaman kopi Liberika & & & $\mathrm{x}$ & & & 3 & 4 \\
\hline 2. & Karakteristik citarasa kopi Liberika & & & & $\mathrm{x}$ & & 2 & 3 \\
\hline 3. & Pengenalan Liberika varietas Robinson & & & $\mathrm{x}$ & & & 3 & 4 \\
\hline 4. & Pemilihan pohon induk entres kopi Liberika & & & & $\mathrm{x}$ & & 2 & 4 \\
\hline 5. & Pemilihan pohon induk benih kopi Liberika & & & & $\mathrm{x}$ & & 2 & 3 \\
\hline 6. & Seleksi benih Liberika & & & $\mathrm{x}$ & & & 3 & 4 \\
\hline 7. & Penyemaian benih Liberika & & $\mathrm{x}$ & & & & 4 & 5 \\
\hline 8. & Pembibitan utama di rumah atap & & & $\mathrm{x}$ & & & 3 & 4 \\
\hline 9. & Pembibitan utama di bedengan & & & $\mathrm{x}$ & & & 3 & 3 \\
\hline 10. & Pemupukan bibit kopi sistem kocor & & & $\mathrm{x}$ & & & 3 & 4 \\
\hline 11. & Pembuatan pupuk organik cair & & & & $\mathrm{x}$ & & 2 & 3 \\
\hline 12. & Manfaat limbah kulit kopi & & & $\mathrm{x}$ & & & 3 & 4 \\
\hline 13. & Pembuatan biochar kulit kopi & & & & & $\mathrm{x}$ & 1 & 2 \\
\hline 14. & Manfaat biochar kulit kopi & & & & & $\mathrm{x}$ & 1 & 2 \\
\hline 15. & Penanaman bibit Liberika & & $\mathrm{x}$ & & & & 4 & 5 \\
\hline 16. & Penyambungan klon kopi Robusta/Liberika & & $\mathrm{x}$ & & & & 4 & 4 \\
\hline 17. & Regenerasi lahan kebun kopi & & & & $\mathrm{x}$ & & 2 & 3 \\
\hline 18. & Produktivitas kebun kopi Robusta/Liberika & & & $\mathrm{x}$ & & & 3 & 4 \\
\hline & Jumlah skor & & & & & & 43 & 65 \\
\hline
\end{tabular}

\section{PENUTUP}

\section{Kesimpulan}

a. Pengabdian masyarakat "Demplot Pembibitan Kopi Liberika di Desa Puralaksana, Kecamatan Way Tenong, Sumberjaya, Kabupaten Lampung Barat sudah dilaksanakan dengan peserta dari Kelompok Tani Makmur Utama melalui kegiatan penyuluhan, FGD, anjangsana dan anjangkarya dan pendampingan penguatan kelompok.

b. Pengabdian ini dapat meningkatkan pengetahuan dan keterampilan petani dalam pembibitan kopi Liberika dan budidaya kopi sambungan Robusta/Liberika untuk meningkatkan ketahanan dan produktivitas kopi pada cuaca ekstrim dengan skore 65 berkategori baik.

\section{Saran}

Agar dikembangkan kopi Liberika berbagai varietas Robinson asal Lampung Barat dan dipelajari karakter keunggulannya.

Agar dikembangkan sistem klonisasi kopi dengan batang bawah kopi Liberika agar lebih toleran terhadap cekaman lingkungan ekstrim.

\section{DAFTAR PUSTAKA}

[1] Direktorat Jenderal Perkebunan. 2018. Statistik Perkebunan Indonesia Komoditas Kopi 2017-2019. Kementerian Pertanian. Jakarta. $79 \mathrm{hlm}$.

[2] BPS Kabupaten Lampung Barat. (2020). Kabupaten Lampung Barat Dalam Angka 2020. Liwa. 204 hlm.

[3] BPS Kabupaten Lampung Barat. (2018). Kecamatan Way Tenong Dalam Angka 2018. Liwa. $50 \mathrm{hlm}$.

[4] Panhuysen, S., \& Pierrot, J. (2014). Barómetro de café 2014. Federación Nacional de Cafeteros de Colombia. Ensayos sobre economía cafetera, 27(30). 
[5] Evizal, R., Sugiatno, S., \& Prasmatiwi, F. E. (2015). Ragam kultivar kopi di Lampung. Agrotrop, 5(1), 8088.

[6] Evizal, R., Sugiatno, S., Prasmatiwi Erry, F., \& Nurmayasari, I. (2016). Shade tree species diversity and coffee productivity in Sumberjaya, West Lampung, Indonesia. Biodiversitas Journal of Biological Diversity, 17(1), 234-240. 